\title{
Determination of synthetic phenolic antioxidants and relative metabolites in sewage treatment plant and recipient river by high performance liquid chromatography-electrospray tandem mass spectrometry
}

\author{
Runzeng Liu, Ting Ruan, Shanjun Song, Yongfeng Lin, Guibin Jiang* \\ State Key Laboratory of Environmental Chemistry and Ecotoxicology, Research Center for Eco-Environmental Sciences, Chinese Academy of Sciences, \\ Beijing 100085, China
}

\section{A R T I C L E I N F O}

\section{Article history:}

Received 30 September 2014

Received in revised form

14 November 2014

Accepted 14 November 2014

Available online 21 November 2014

\section{Keywords:}

Synthetic phenolic antioxidants

Metabolites

Liquid chromatography-tandem mass

spectrometry

Sludge

Sewage effluent

Recipient river

\begin{abstract}
A B S T R A C T
Robust analytical methods were developed for the determination of eight emerging synthetic phenolic antioxidants (SPAs) and three metabolites in sewage sludge, effluent and river water matrices. Accelerated solvent extraction was employed for the extraction of the target analytes from sludge, dichloromethane/hexane $=3: 1$ (extraction solvent) and $90^{\circ} \mathrm{C}$ (extraction temperature) were used after optimization. Silica gel packed column was chosen for the subsequent cleanup procedure for sludge extract. For the water sample analysis, liquid-liquid extraction combined with silica gel clean-up was used. The targets were determined by optimized high performance liquid chromatography-tandem mass spectrometry method in negative electrospray ionization mode. The method quantification limits of the 11 analytes ranged from 0.1 to $23 \mathrm{ng} / \mathrm{L}, 0.1$ to $20 \mathrm{ng} / \mathrm{L}$ and 0.1 to $15 \mathrm{ng} / \mathrm{g}$ for sewage effluent, river water and sludge matrices, respectively. The total recoveries of the pretreatment varied from 63 to 106\%, with relative standard deviations less than $17 \%$ for the three matrices at different spiking levels. Nine targets including 2,6-di-tert-butyl-4-methylphenol (BHT), 3,5-di-tert-butyl-4-hydroxybenzaldehyde (BHT-CHO), 2,6di-tert-butyl-1,4-benzoquinone (BHT-Q), 2,6-di-tert-butyl-4-hydroxy-4-methyl-2,5-cyclohexadienone (BHT-quinol), 3-tert-butyl-4-hydroxyanisole (BHA), 4-tert-octylphenol (4-tOP), 2,2'-methylenebis(6tert-butyl-4-methylphenol) (AO 2246), 4,4'-butylidenebis(2-(1,1-dimethylethyl)-5-methyl-phenol) (AO 44B25) and 1,3,5-trimethyl-2,4,6-tris(3,5-di-tert-butyl-4-hydroxybenzyl)benzene (AO 330) were identified in the collected samples, with concentrations ranging $1.1-2325 \mathrm{ng} / \mathrm{g}$ and $0.4-2510 \mathrm{ng} / \mathrm{L}$ for sludge and water matrices, respectively. Sewage effluent was considered as a possible contamination source of certain SPA homologues and relative metabolites to the recipient aquatic systems.
\end{abstract}

(C) 2015 Published by Elsevier B.V.

\section{Introduction}

All polymeric materials undergo oxidation reactions and the most commonly used protection protocol is the addition of antioxidants (AOs), in which synthetic phenolic antioxidants (SPAs) are the most frequently used AO additives [1,2]. SPAs, represented by 2,6-di-tert-butyl-4-methylphenol (BHT), usually share a basic common structure characterized by phenolic ring which is substituted with hindered alkyl groups in orthopositions [3]. Toxicity studies showed that the metabolites

\footnotetext{
* Corresponding author. Tel.: +86 106284 9334; fax: +86 1062849179

E-mail address: gbjiang@rcees.ac.cn (G. Jiang).
}

of BHT, such as 3,5-di-tert-butyl-4-hydroxybenzaldehyde (BHTCHO), 2,6-di-tert-butyl-1,4-benzoquinone (BHT-Q) and 2,6-dit-butyl-4-hydroxy-4-methyl-2,5-cyclohexadienone (BHT-quinol), could generate peroxides in mice and rats and induce cellular DNA damage [4]. 3-Tert-butyl-4-hydroxyanisole (BHA) may modulate and disrupt the endocrine system, and was even suspected to be carcinogenic [5,6]. 4,4'-Butylidenebis(2-(1,1-dimethylethyl)5-methyl-phenol) (AO 44B25) was demonstrated to has strong androgen receptor and estrogen receptor antagonist activities in vitro assays, with the strength of these activities similar to that of bisphenol A [7]. 2,2'-Methylenebis(4-methyl-6-tert-butylphenol) (AO 2246) was found as direct testicular toxin in rats [8].

The SPAs could be released into environment during production processes and massive applications such as household usages 
[9]. Just like other pollutants, most of the SPAs released from industrial and domestic areas could be gathered to wastewater treatment plants (WWTPs) [9], reliable analytical methods to monitor them in sewage effluent, sludge and thereafter the river water which receives WWTP effluent are therefore essential to understand their environmental occurrence and fate. Besides, using time-of-flight mass spectrometry for nontarget screening of organic pollutants, BHT and BHT-CHO were universally found in surface waters and soils from rice production area [10], which further suggests the importance of investigation on this kind of emerging pollutants. To our knowledge, only few methods for the determination of SPAs in the environment could be found. The existing analytical methods were mainly limited in analyzing BHA, BHT and related metabolites in water and food simulate (acetic acid, ethanol and soybean oil) samples, with solid phase extraction (SPE) as pretreatment procedure $[1,11,12]$. The other emerging SPAs with high hydrophobicities, which include 4,4'-methylenebis(2,6-di-tert-butylphenol) (AO 4426), AO 44B25 and 2,2'-methylenebis(6-cyclohexyl-4methyl)phenol (AO ZKF), were not involved in these methods. Gas chromatography-mass spectrometry (GC-MS) was successfully applied to determinate BHA, BHT, BHT-Q and BHT-CHO $[1,3,11,13]$; however, it might not be applicable for simultaneously analyzing various SPAs with high molecular weights and low volatilities.

In this study, efficient methods were developed for the simultaneous analysis of eight SPAs and three BHT metabolites in sewage sludge, effluent and river water matrices. The affecting parameters during the sample extraction and cleanup procedures were optimized. The target compounds were analyzed by high performance liquid chromatography-tandem mass spectrometer (HPLC-MS/MS). Finally the developed methods were evaluated and applied to the analysis of the targets in sewage sludge, effluent samples from a WWTP in Beijing, and water samples from a river which receives the WWTP effluent.

\section{Experimental}

\subsection{Chemicals and reagents}

Analyte name, structure and other relevant data are shown in Table 1 [14]. BHT-quinol was supplied by Frontier Scientific, Inc. (Logan, USA). Certified standards of other analytes were obtained from TCI (Tokyo, Japan). The purities for all the target analytes were $>95 \%$. Isotope-labeled tetrabromobisphenol A (rings- ${ }^{13} \mathrm{C}_{12}$; purity 99\%) and 2,6-di-(tert-butyl-d9)-4-methyl (phenol-3,5,0-d3) (BHT-d21; purity 98\%) were purchased from Cambridge Isotope Laboratories (Andover, USA). Stock standard solutions $(1000 \mu \mathrm{g} / \mathrm{mL})$ were individually prepared in methanol and intermediate solutions were weekly prepared from the stock standard solutions by appropriate methanol dilution. Silica gel (100-200 mesh size, Merck, Darmstadt, Germany) was activated at $550^{\circ} \mathrm{C}$ for $12 \mathrm{~h}$, florisil (60-100 mesh, Sigma-Aldrich, St. Louis, USA) was activated at $140^{\circ} \mathrm{C}$ for $7 \mathrm{~h}$, while alumina (100-200 mesh, Sinopharm Chemical Reagent, Shanghai, China) was activated at $600{ }^{\circ} \mathrm{C}$ for $6 \mathrm{~h}$. All the three pretreatment sorbents were $5 \%$ waterdeactivated prior to use. Anhydrous sodium sulfate $\left(\mathrm{Na}_{2} \mathrm{SO}_{4}\right)$ was baked at $600^{\circ} \mathrm{C}$ for $6 \mathrm{~h}$ and stored in a sealed desiccator. Sep-pak C18 $\left(6 \mathrm{~cm}^{3}, 500 \mathrm{mg}\right)$ and Oasis HLB $\left(6 \mathrm{~cm}^{3}, 150 \mathrm{mg}\right)$ SPE cartridges were purchased from Waters (Milford, USA). All solvents were of HPLC grade. Dichloromethane (DCM), hexane (Hex) and methanol $(\mathrm{MeOH})$ were obtained from J.T. Baker (Phillipsburg, USA). Ultrapure water $(18.3 \mathrm{M} \Omega \mathrm{cm}$ ) was generated by a Milli-Q purification system (Millipore, Billerica, USA).

\subsection{Sample collection}

Twenty-four hour integrated samples of sewage effluent $(n=4)$ were taken from a WWTP in Beijing, China during November 6-9, 2013. The investigated WWTP in this work has a conventional activated sludge system (anaerobic, anoxic, and oxic tanks) with an average domestic wastewater flow of $200000 \mathrm{~m}^{3} \mathrm{~d}^{-1}$. Water samples $(n=4)$ were also taken from the Qing river which receives sewage effluent from the WWTP in November 8 . The intersection of the river and the WWTP outlet was set as starting point. One upstream $(-500 \mathrm{~m})$ river water sample and three downstream $(500 \mathrm{~m}, 1000 \mathrm{~m}, 1500 \mathrm{~m})$ water samples were collected along the recipient river. At each site, $500 \mathrm{~mL}$ water was collected and stored in a brown glass bottle. All vessels were precleaned with $\mathrm{MeOH}$ and ultrapure water to avoid contamination. All the water samples were extracted as soon as possible after centrifugation at $5000 \mathrm{rpm}$ for $10 \mathrm{~min}$ to eliminate suspended solid matters. Sludge samples $(n=4)$ were also collected at the dewatering process from the WWTP during November 6-9, packed in aluminum foil, sealed in polyethylene bags. The sludge samples were frozen-dried, ground, sieved, and stored at $-20^{\circ} \mathrm{C}$ until analysis.

\subsection{Sample preparation}

For the solid sample analysis, $0.5 \mathrm{~g}$ of sludge (spiked with $20 \mathrm{ng}{ }^{13} \mathrm{C}$ TBBPA and $200 \mathrm{ng}$ BHT-d21) was mixed with $15 \mathrm{~g}$ of $\mathrm{Na}_{2} \mathrm{SO}_{4}$ and extracted with DCM/Hex $(3: 1, \mathrm{v} / \mathrm{v})$ at $90^{\circ} \mathrm{C}$ and 1500 psi in three static extraction cycles of 10 min using an accelerated solvent extractor (ASE 350, Dionex, Sunnyvale, USA). The extracts were concentrated by rotary evaporation to $\sim 2 \mathrm{~mL}$ and fractioned on an $8 \mathrm{~g}$ silica gel packed column. Before sample loading, the silica gel was preconditioned by $30 \mathrm{~mL}$ of Hex, and then the concentrated sludge extracts were loaded and eluted with $120 \mathrm{~mL}$ of $\mathrm{DCM} / \mathrm{Hex}(1: 1, \mathrm{v} / \mathrm{v})$ mixtures. The eluates were concentrated, solvent exchanged into $5 \mathrm{~mL}$ of $\mathrm{MeOH}$, with $20 \mu \mathrm{L}$ injected into instrument for quantification analysis. Liquid samples were extracted by liquid-liquid extraction (LLE) method. Briefly, $400 \mathrm{~mL}$ sample (spiked with $40 \mathrm{ng}{ }^{13} \mathrm{C}$ TBBPA and $400 \mathrm{ng}$ BHTd21) was mixed with $100 \mathrm{~mL}$ DCM and shocked for $5 \mathrm{~min}$, after which the DCM was transferred to another glass bottle. The extraction was repeated triply. The combined DCM was concentrated by rotary evaporation to $\sim 2 \mathrm{~mL}$ and fractioned on an $8 \mathrm{~g}$ silica gel packed column as described above. The eluates were then concentrated, solvent exchanged into $1 \mathrm{~mL}$ of $\mathrm{MeOH}$ and injected into HPLC-MS/MS for quantification.

\subsection{Instrumentation}

An Alliance 2695 high performance liquid chromatography interfaced with a Quattro Premier XE triple-quadrupole mass spectrometer (Waters, Milford, USA) was used for quantification purpose. A $150 \times 4.6 \mathrm{~mm}$ Acclaim $^{\circledR} 120 \AA$ C18 analytical column (Dionex, Sunnyvale, USA) was chosen for chromatographic separation. Column temperature was set at $40^{\circ} \mathrm{C}$. $\mathrm{MeOH}(\mathrm{A})$ and ultrapure water (B) were chosen as mobile phases. The gradient was initiated at a composition of 90:10 (A:B, v/v). The gradient elution program was optimized with composition A linearly increased to $100 \%$ in $5 \mathrm{~min}$ and then held for $15 \mathrm{~min}$. After immediately returning to the initial composition, the column was allowed to re-equilibrate for $3 \mathrm{~min}$, which gave a total time of $23 \mathrm{~min}$. Flow rate for the separation procedure was set at $0.3 \mathrm{~mL} / \mathrm{min}$. Mass spectrometer was operated in negative electrospray ionization (ESI) mode. The source and desolvation temperature were set at 120 and $450^{\circ} \mathrm{C}$, respectively. Desolvation gas flow was $800 \mathrm{~L} / \mathrm{h}$, cone gas flow was $50 \mathrm{~L} / \mathrm{h}$, while argon pressure in the collision cell was kept at $3.5 \times 10^{-3} \mathrm{mbar}$ for MS/MS measurement. Detailed information on the optimized 
Table 1

Analyte name, structure and other relevant data.

\begin{tabular}{|c|c|c|c|c|}
\hline Acronym & Chemical name & Structure & CAS & $\log K_{o w}{ }^{\mathrm{a}}$ \\
\hline BHT & 2,6-Di-tert-butyl-4-methylphenol & & $128-37-0$ & 5.03 \\
\hline $\mathrm{BHT}-\mathrm{CHO}$ & 3,5-Di-tert-butyl-4-hydroxybenzaldehyde & & $1620-98-0$ & 4.20 \\
\hline BHT-Q & 2,6-Di-tert-butyl-1,4-benzoquinone & & $719-22-2$ & 4.42 \\
\hline BHT-quinol & 2,6-Di-tert-butyl -4-hydroxy-4-methyl-2,5-cyclohexadienone & & $10396-80-2$ & 3.72 \\
\hline $\mathrm{BHA}$ & 3-Tert-butyl-4-hydroxyanisole & & $121-00-6$ & 3.50 \\
\hline $4-t \mathrm{OP}$ & 4-Tert-octylphenol & & $140-66-9$ & 5.28 \\
\hline AO 2246 & 2,2'-Methylenebis(6-tert-butyl-4-methylphenol) & & $119-47-1$ & 7.97 \\
\hline AO 4426 & 4,4'-Methylenebis(2,6-di-tert-butylphenol) & & $118-82-1$ & 8.99 \\
\hline AO 44B25 & 4,4'-Butylidenebis(2-(1,1-dimethylethyl)-5-methyl-phenol) & & $85-60-9$ & 9.09 \\
\hline AO ZKF & 2,2'-Methylenebis(6-cyclohexyl-4-methyl)phenol & & $4066-02-8$ & 9.78 \\
\hline
\end{tabular}


Table 1 (Continued)

\begin{tabular}{|c|c|c|c|c|}
\hline Acronym & Chemical name & Structure & CAS & $\log K_{o w}{ }^{a}$ \\
\hline AO 330 & 1,3,5-Trimethyl-2,4,6-tris(3,5-di-tert-butyl-4-hydroxybenzyl)benzene & & $1709-70-2$ & 17.17 \\
\hline
\end{tabular}

${ }^{\text {a }} \log K_{o w}$ values obtained from [14].

parameters and monitored ion transitions for each analyte is given in Table S1.

\subsection{Method validation}

Procedures were carried out to validate the optimized SPA determination methods. In this study, sample quantification was based on an external calibration method along with the internal standard recovery correction. The concentrations of single phenolic ring analytes (BHT, BHT-CHO, BHT-Q, BHT-quinol, BHA and 4-tOP) were corrected by BHT-d21, while the concentrations of the SPAs with more than one phenolic ring (AO 2246, AO 4426, AO 44B25, $\mathrm{AO}$ ZKF and AO 330) were corrected by ${ }^{13} \mathrm{C}$ TBBPA. The linearity range of the standard calibration curve was evaluated by injecting 10 concentration levels of standard $(1,2,5,10,20,50,100,200$, $500,1000 \mathrm{ng} / \mathrm{mL}$ ) for all the studied compounds except BHT, which was prepared at concentrations from 20 to $2000 \mathrm{ng} / \mathrm{mL}$ due to its low response. Method quantification limits (MQLs) were defined as the analyte concentrations corresponding to signal-to-noise ratio of 10 in different matrices. The recoveries and accuracies of the target analytes except BHT were obtained by spiking sludge samples (40 and $200 \mathrm{ng} / \mathrm{g}$ ) and water samples (100 and $500 \mathrm{ng} / \mathrm{L}$ ) at two different concentrations. The spiking levels of BHT (400 and $2000 \mathrm{ng} / \mathrm{g}$ for sludge matrix, 1000 and $5000 \mathrm{ng} /$ L for water matrices) were 10 times higher than other analytes. The background concentrations of SPAs and BHT metabolites in the non-spiked samples were determined and then subtracted from the total concentrations to determine the absolute recoveries. The internal standards were added to the sludge and water samples when evaluating the performance of the method, in order to take the potential losses during pretreatment procedures into consideration. When analyzing the collected samples, procedural blank samples $\left(15 \mathrm{~g} \mathrm{Na}_{2} \mathrm{SO}_{4}\right.$ for sludge samples, $400 \mathrm{~mL}$ Milli-Q water for sewage effluent and river water samples) were added to every batch of the samples to check for the potential contaminations in the pretreatment procedures. Besides, in order to check for potential instrumental contamination, $\mathrm{MeOH}$ was routinely injected into the instrument during sample processing sequences.

\section{Results and discussion}

\subsection{Determination of sludge samples}

\subsubsection{Clean-up procedure for sludge extracts}

Quantification analysis of chemicals in complex environmental matrices by LC-(ESI)-MS/MS is often subjected to serious ionization suppression/enhancement by co-eluting compounds [15-19]. And clean-up procedures for the sludge extracts were usually carried out before sample injection $[17,20]$.

Normal phase sorbent packed columns were commonly used for the clean-up of sludge extracts and other samples when analyzing pollutants with high $\log K_{o w}$ [21]. Alumina, florisil and silica gel were used to clean up the extracts of biological tissues and sludge matrix when analyzing alkylphenols, benzotriazole UV stabilizers, chlorobenzenes and polybrominated diphenyl ethers [22-26]. In this study, the optimization of the clean-up procedure was first carried out with pure standards. In order to select proper normal phase sorbents for the target SPAs and metabolites, $100 \mathrm{ng}$ analyte mixtures were passed through $8 \mathrm{~g}$ florisil, alumina or silica gel packed columns to investigate the corresponding recoveries. All the normal phase packed columns were preconditioned by $30 \mathrm{~mL}$ of Hex, and after loading, the analytes were eluted with $80 \mathrm{~mL}$ of different DCM/Hex mixtures $(1: 3,1: 1$ or $3: 1, v / v)$. Finally, the eluates were concentrated, solvent exchanged into $1 \mathrm{~mL}$ of $\mathrm{MeOH}$ and injected into the instrument for analysis. As shown in Fig. 1, florisil brought low recoveries (5-13\%) for BHA, AO 2246, AO 44B25, AO ZKF and AO 330, while alumina produced low recoveries (5-28\%) for 4-tOP, 44B25 and AO ZKF, which implied the excessive strong adsorption of these compounds on florisil and alumina, respectively. Silica gel provided higher recoveries for most target analytes compared with florisil and alumina, no matter which eluting solvent was used, and was thus selected to use in the following experiment. Eluting solvent can affect the recoveries of most target analytes through silica gel packed column, especially for BHT and AO 44B25. High recoveries were obtained when the eluting solvents were $\mathrm{DCM} / \mathrm{Hex}=1: 1$ (56-112\%) and DCM/Hex = 3:1 (74-114\%). Finally, the middle-polarity mixture $\mathrm{DCM} / \mathrm{Hex}=1: 1$ was chosen to be used as eluting solvent to get satisfactory recoveries and avoid too much co-eluting interferents from sludge extracts when analyzing real samples. The volume of the eluting solvent $(\mathrm{DCM} / \mathrm{Hex}=1: 1)$ was also investigated. In order to check if $80 \mathrm{~mL}$ solvent was enough, after the first $80 \mathrm{~mL}$ elution, another $40+40 \mathrm{~mL}$ solvent was used and determined separately. Results showed that no target analytes existed in the $80-120 \mathrm{~mL}$ section except AO 44B25. The recovery of AO 44B25 increased from 56 to $77 \%$ when the eluting solvent volume increased from 80 to $120 \mathrm{~mL}$, however, no obvious recovery increase was found when the volume further increased to $160 \mathrm{~mL}$. Therefore, $120 \mathrm{~mL}$ of $\mathrm{DCM} / \operatorname{Hex}(1: 1, \mathrm{v} / \mathrm{v})$ was decided to be used.

Once the silica gel clean-up procedure was optimized using pure standards, the proposed method was applied to sludge extracts spiked with $100 \mathrm{ng}$ standard mixtures. Compared with the target recoveries (77-112\%) in pure solvent, the target recoveries in sludge extracts were relatively lower (26-96\%), which might be influenced by matrix ionization suppression. 


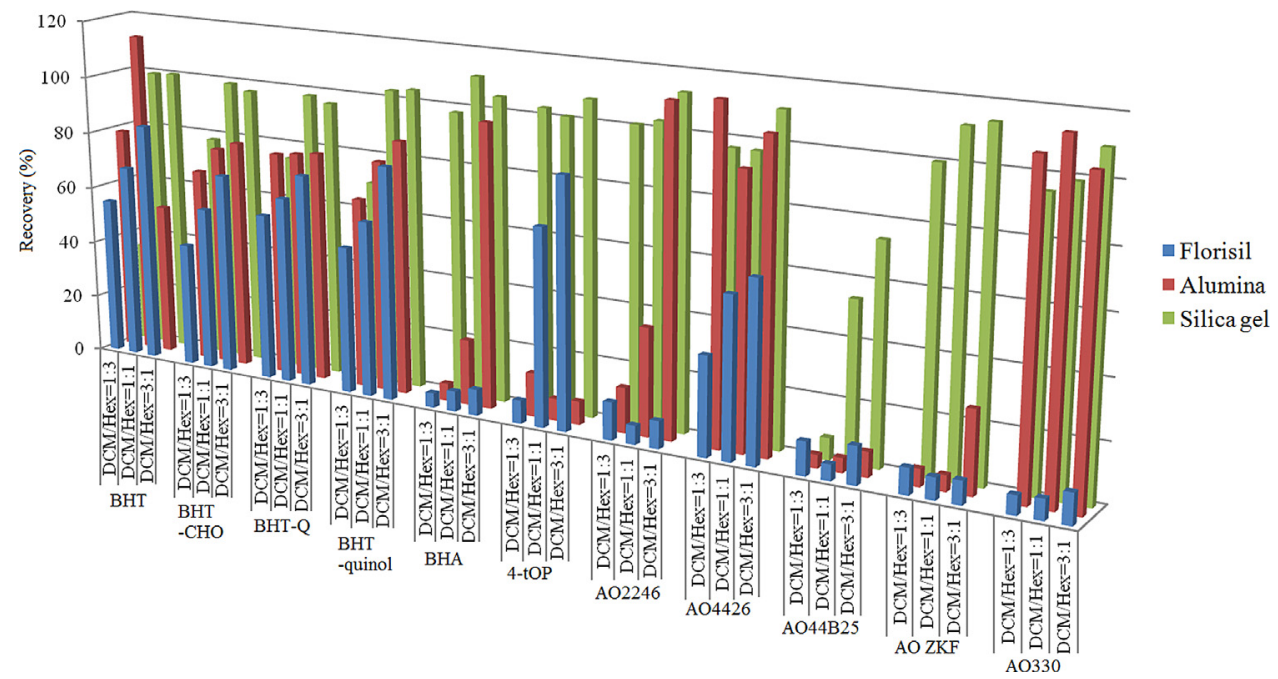

Fig. 1. Recoveries of the targets through different normal phase sorbents and eluting solvents $(n=3)$.

\subsubsection{Decrease of matrix effect by sample dilution}

Matrix effects for the target analytes were represented by the percentage of signal response in sample matrix versus the signal of the same concentration in $\mathrm{MeOH}$. Matrix effect larger than $100 \%$ means ionization enhancement, while matrix effect little than $100 \%$ implies ionization suppression. In this study, spiked eluates ( $100 \mathrm{ng})$ of $0.5 \mathrm{~g}$ sludge samples from silica gel packed columns were used as tested samples. The spiked eluates were concentrated to dry, dissolved in $1 \mathrm{~mL}$ of $\mathrm{MeOH}$ and injected. Results in Fig. 2 shows that no severe ionization enhancement or suppression was found for BHT-CHO, BHT-Q, BHT-quinol, BHA and AO ZKF, with matrix effects within the range of $80-120 \%$. Meanwhile, different degrees of ionization suppressions were observed for the other six analytes, with matrix effects varying from 28 to $76 \%$.

Different methods, such as improvement of the clean-up of sample extracts, are used to decrease the matrix effect during LC-MS/MS determination [20,21]. However, many authors consider these possible methods as time consuming. Besides, they can also increase the risk of analyte loss or sample contamination during the prolonged pretreatment [27]. Dilution of samples before injection is an effective method to reduce matrix effect without prolonging the handling. It has been employed to reduce the matrix effects when analyze polyether ionophores [28], sulfonamide antibiotics [27] in urban sewage sludge and pesticides in fruits and vegetables [29]. In this study, the spiked sludge eluates were concentrated to dry, dissolved in different volumes $(2,5$ and $10 \mathrm{~mL})$ of $\mathrm{MeOH}$ and injected to ascertain the reduction of matrix effects achieved by sample dilution. As shown in Fig. 2, ionization suppressions of these six analytes (BHT, 4-tOP, AO 2246, AO 4426, AO 44B25 and $\mathrm{AO} 330$ ) were reduced when the dilution volume increased from $1 \mathrm{~mL}$ to $10 \mathrm{~mL}$. When the final sample volume was adjusted to 5 and $10 \mathrm{~mL}$, satisfactory matrix effects within the range of $80-120 \%$ were observed for all the targets, which facilitates accurate analysis of the SPA analytes in sludge samples. Finally, dilution volume of $5 \mathrm{~mL}$ was chosen as optimal, taking the matrix effects and MQLs into consideration.

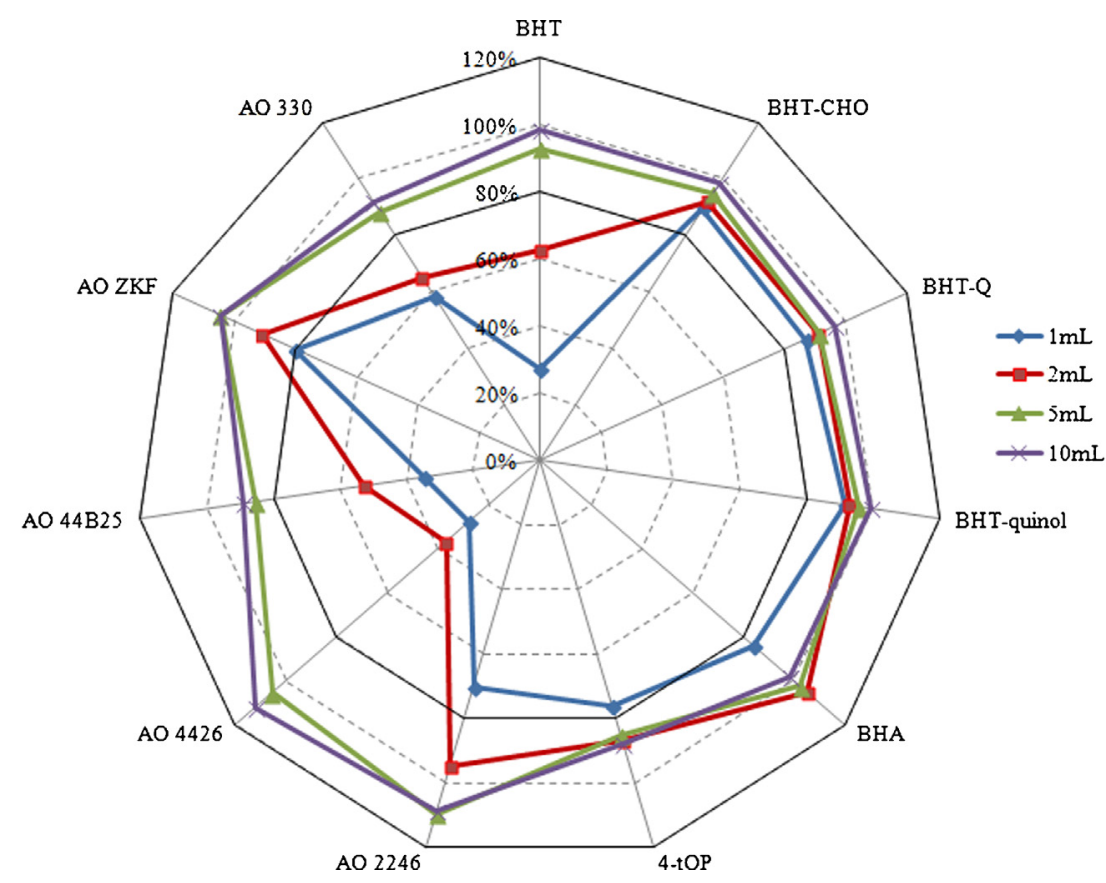

Fig. 2. Matrix effects of the targets after different volumes of dilution $(n=3)$. 

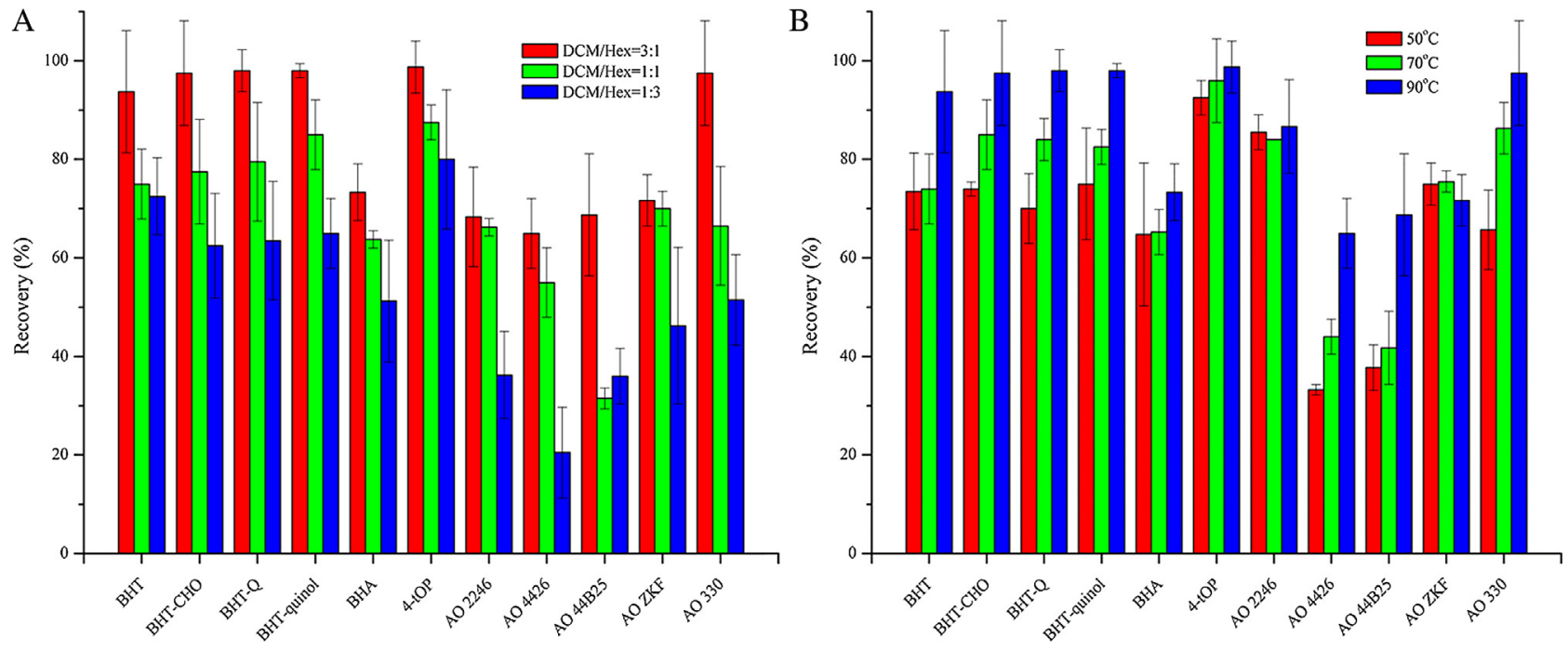

Fig. 3. Optimization of the affecting factors on ASE including (A) extraction solvent and (B) temperature $(n=3)$.

\subsubsection{Extraction of sludge samples}

ASE was commonly used to extract analytes from solid matrix samples [21,23]. An efficient extraction of analytes from solid samples with ASE method involves the optimization of some parameters, in which extraction solvent and temperature are the most important ones [21,30]. DCM/Hex mixtures were demonstrated to be proper to extract various pollutants from sludge matrix [21]. In this study, DCM/Hex mixtures $(1: 3,1: 1,3: 1, \mathrm{v} / \mathrm{v})$ were tested for the extraction of SPAs and the metabolites from the spiked sludge samples ( $200 \mathrm{ng} / \mathrm{g}$ ). The sludge extracts were cleaned by silica gel packed columns in the optimized conditions. Results in Fig. 3(A) shows that extraction solvent had a considerable impact on target recoveries. $\mathrm{DCM} / \mathrm{Hex}=3: 1$ provided the most satisfactory results among the three extraction solvents, with recoveries varying from 65 to $99 \%$.

Temperature is another important impacting factor on extraction efficiency during the ASE process $[21,27]$. The extraction temperature was tested at 50,70 and $90^{\circ} \mathrm{C}$ with the same conditions stated above. As shown in Fig. 3(B), different extraction temperature had different extraction efficiencies for all the compounds, with $90^{\circ} \mathrm{C}$ giving the best recoveries (65-98\%) for most analytes. The high extraction efficiency of $90^{\circ} \mathrm{C}$ might due to that high temperature decreases the viscosity of extraction solvent and promotes the solvent penetration through the sludge matrix [27]. Besides, in order to check the efficient extraction of the first three cycles, a consecutive fourth extraction was performed and did not lead to a quantifiable recovery improvement.

\subsection{Determination of water samples}

Two different extraction methods were optimized and compared for sewage effluent and river water samples during method development procedures: (1) SPE with C18 and HLB cartridges; (2) LLE.

\subsubsection{SPE optimization for water samples}

When selecting cartridges, SPE adsorption mechanism and analyte characteristics should be taken into account [31]. Considering the large range of log $K_{\text {ow }}$ (3.50-9.78) for the target SPAs and BHT metabolites, SPE cartridges including C18 and HLB were tested to extract the target analytes from water samples in this study. AO 330 was not included in the analysis of water samples, due to its
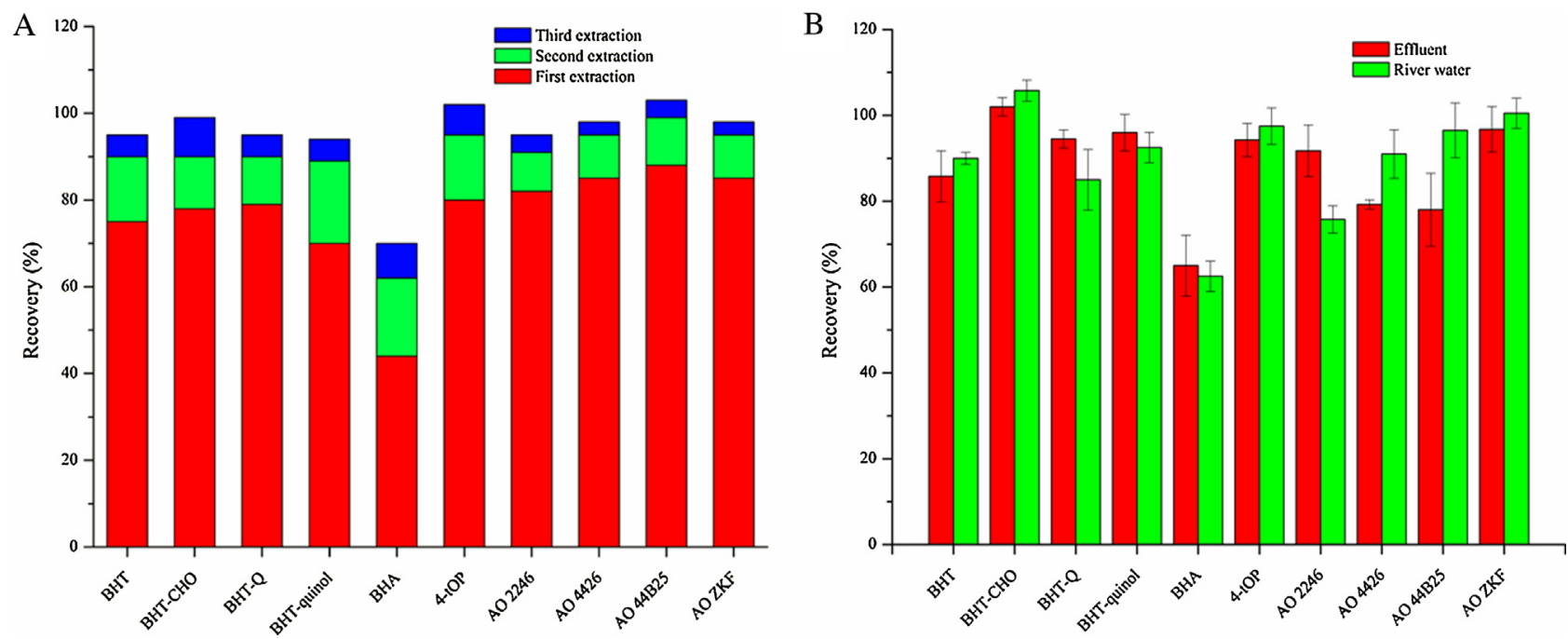

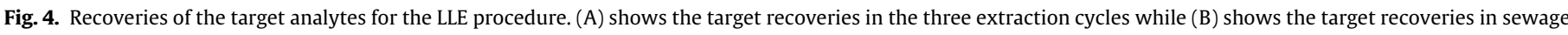
effluent and river water $(n=3)$. 
Table 2

Validation data and performance of the optimized method.

\begin{tabular}{|c|c|c|c|c|c|c|c|c|c|c|}
\hline \multirow[t]{3}{*}{ Compound } & \multicolumn{3}{|c|}{ Method quantification limits } & \multirow[t]{3}{*}{ Linearity $/ R^{2}$} & \multicolumn{6}{|c|}{ Recovery (\%RSD) } \\
\hline & \multirow[t]{2}{*}{ Effluent (ng/L) } & \multirow[t]{2}{*}{ River water (ng/L) } & \multirow[t]{2}{*}{ Sludge (ng/g) } & & \multicolumn{2}{|l|}{ Effluent } & \multicolumn{2}{|l|}{ River water } & \multicolumn{2}{|l|}{ Sludge } \\
\hline & & & & & 100 (ng/L) & $500(\mathrm{ng} / \mathrm{L})$ & $100(\mathrm{ng} / \mathrm{L})$ & $500(\mathrm{ng} / \mathrm{L})$ & $40(\mathrm{ng} / \mathrm{g})$ & 200 (ng/g) \\
\hline $\mathrm{BHT}^{\mathrm{a}}$ & 23 & 20 & 15 & 0.993 & $81(4)$ & $86(7)$ & $84(8)$ & $90(8)$ & $94(13)$ & $93(11)$ \\
\hline BHT-CHO & 2.3 & 2.0 & 3.0 & 0.999 & $98(8)$ & $102(7)$ & $101(8)$ & $106(3)$ & $102(8)$ & $97(5)$ \\
\hline BHT-Q & 1.5 & 1.1 & 0.7 & 0.998 & $105(10)$ & $95(9)$ & $89(6)$ & $85(8)$ & $95(6)$ & $93(6)$ \\
\hline BHT-quinol & 0.7 & 0.5 & 0.8 & 0.998 & $100(10)$ & $96(8)$ & $86(7)$ & $93(4)$ & $94(13)$ & $94(10)$ \\
\hline BHA & 0.6 & 0.5 & 1.2 & 0.998 & $63(9)$ & $65(10)$ & $63(17)$ & $63(6)$ & $73(8)$ & $81(7)$ \\
\hline 4-tOP & 1.2 & 1.0 & 1.4 & 0.998 & $100(10)$ & $94(4)$ & $95(8)$ & $98(4)$ & $99(5)$ & $103(6)$ \\
\hline AO 2246 & 0.3 & 0.2 & 0.3 & 0.999 & $72(14)$ & $76(9)$ & $90(7)$ & $92(4)$ & $74(7)$ & $87(11)$ \\
\hline AO 4426 & 1.5 & 1.3 & 1.6 & 0.998 & $90(16)$ & $80(12)$ & $89(6)$ & $91(6)$ & $70(13)$ & $65(10)$ \\
\hline AO 44B25 & 1.1 & 1.0 & 1.0 & 0.999 & $80(14)$ & $78(11)$ & $74(6)$ & $76(7)$ & $71(12)$ & $74(11)$ \\
\hline $\mathrm{AO} \mathrm{ZKF}$ & 0.1 & 0.1 & 0.4 & 0.999 & $90(12)$ & $97(6)$ & $84(12)$ & $101(4)$ & $74(7)$ & $89(6)$ \\
\hline AO 330 & $-\mathrm{b}$ & $-\mathrm{b}$ & 1.0 & 0.998 & $-\mathrm{b}$ & $-\mathrm{b}$ & $-\mathrm{b}$ & b & $98(11)$ & 87 (9) \\
\hline
\end{tabular}

a The spiking levels of BHT were 10 times higher than other analytes.

b AO 330 was not included in the analysis of water matrices.

excessively minor solubility $\left(\log K_{o w}=17.17\right)$. The SPE procedures were first optimized using $100 \mathrm{~mL}$ standard spiked ultrapure water $(1000 \mathrm{ng} / \mathrm{L}$ ) and were shown in the supporting information (Section S2). As shown in Table S2 and S3, C18 showed higher recoveries (56-116\%) than HLB (25-97\%). Once the SPE procedure was optimized using spiked ultrapure water, the C18 cartridges were applied to $100 \mathrm{~mL}$ of standard spiked effluent and river water samples (1000 ng/L). Results listed in Table S4 shows that the recoveries of target analytes were $15-94 \%$ and $13-86 \%$ for river water and sewage effluent, respectively. Low recoveries were found for BHA (15\%) and AO 4426 (38\%) in river water matrix. For sewage effluent, unfortunately, low recoveries $(<37 \%)$ were found for all compounds except 4-tOP and the three BHT metabolites. The low recoveries of these target analytes might due to the severe ionization suppression caused by the interferents in the complex effluent matrix.

\subsubsection{LLE optimization for water samples}

In LLE procedure, extraction solvent is one of the most important factors influencing the extraction efficiency [32]. Based on the solvent selected in literature [33] and the above extraction for sludge matrix, DCM was used for the extraction of water samples. For the optimization procedure, $400 \mathrm{~mL}$ of ultrapure water samples (500 ng/L spiked) were subjected to extraction with $3 \times 100 \mathrm{~mL}$ DCM for three times. All the extracts were passed through $\mathrm{Na}_{2} \mathrm{SO}_{4}$ columns to remove residual moisture. The three extracts were then concentrated, solvent changed into $1 \mathrm{~mL}$ of $\mathrm{MeOH}$ and injected separately. Results in Fig. 4(A) shows that the recoveries of the target analytes were $44-88 \%, 9-19 \%$ and $3-7 \%$ for the first, second and third extraction, respectively, which lead to the total recoveries ranging from 70 to $102 \%$. Furthermore, in order to confirm if three time extractions were enough, a fourth extraction was conducted with $100 \mathrm{~mL}$ DCM after the first three extractions. The target residuals in the fourth extraction were all less than $2 \%$ or below MQLs, which demonstrated the high extraction efficiencies of the first three extractions. Once the LLE procedure was optimized, the proposed method was applied to $400 \mathrm{~mL}$ of standard spiked effluent and river water samples $(500 \mathrm{ng} / \mathrm{L})$. In order to maximize the elimination of matrix effects, the extracts were subjected to silica gel clean-up followed the same procedure as for sludge extracts. As shown in Fig. 4(B), comparable target recoveries were found for sewage effluent (65-102\%) and river (63-106\%) water matrices compared with ultrapure water (70-102\%).

SPE method was first tried to extract the target analytes from water samples, however, low recoveries were found for most SPAs in sewage effluent probably due to the insufficient abilities of SPE cartridges to remove interferents from the effluent matrix, which lead to severe ionization suppression. LLE combined with silica gel clean-up was demonstrated to be suitable for pretreating sewage effluent and river water samples, thus, was chosen to use.

\subsection{Method validation}

All the analytes were under MQLs in procedural blank samples ( $400 \mathrm{~mL}$ ultrapure water) during the LLE. However, BHT contaminations (about $500 \mathrm{ng} / \mathrm{mL}$ ) were found in blank samples $\left(15 \mathrm{~g} \mathrm{Na}_{2} \mathrm{SO}_{4}\right)$ during the ASE procedure. The contamination was confirmed to

Table 3

Concentrations of detected SPAs and BHT metabolites in sludge and water samples.

\begin{tabular}{|c|c|c|c|c|c|c|c|c|c|c|c|c|}
\hline \multirow[t]{3}{*}{ Compound } & \multicolumn{4}{|c|}{ Concentrations of sludge samples (ng/g) } & \multicolumn{8}{|c|}{ Concentrations of water samples (ng/L) } \\
\hline & \multirow[t]{2}{*}{ Sludge 1} & \multirow[t]{2}{*}{ Sludge 2} & \multirow[t]{2}{*}{ Sludge 3} & \multirow[t]{2}{*}{ Sludge 4} & \multicolumn{4}{|c|}{ Sewage effluent } & \multicolumn{4}{|c|}{ River water } \\
\hline & & & & & Effluent 1 & Effluent 2 & Effluent 3 & Effluent 4 & $\begin{array}{l}500 \mathrm{~m} \\
\text { Upstream }\end{array}$ & $\begin{array}{l}500 \mathrm{~m} \\
\text { Downstream }\end{array}$ & $\begin{array}{l}1000 \mathrm{~m} \\
\text { Downstream }\end{array}$ & $\begin{array}{l}1500 \mathrm{~m} \\
\text { Downstream }\end{array}$ \\
\hline BHT & 2325 & 1325 & 1800 & 1400 & 2120 & 2324 & 2510 & 2200 & 104 & 1115 & 500 & 101 \\
\hline BHT-CHO & 101.0 & 131.5 & 104.5 & 57.5 & 110.0 & 95.4 & 90.3 & 105.4 & 15.4 & 80.1 & 40.2 & 30.2 \\
\hline BHT-Q & 129.0 & 404.4 & 367.0 & 938.5 & 2015.0 & 2230.4 & 2501.0 & 1995.2 & 20.1 & 1621.0 & 421.2 & 305.0 \\
\hline BHT-quinol & 127.4 & 376.5 & 384.5 & 967.0 & 1670.4 & 1591.2 & 1810.0 & 1720.6 & 18.4 & 1340.0 & 320.4 & 211.5 \\
\hline BHA & 7.2 & 7.5 & 9.0 & 7.1 & 1.6 & 0.9 & 1.3 & 1.2 & n.d. ${ }^{a}$ & n.d. ${ }^{a}$ & n.d. ${ }^{\mathrm{a}}$ & n.d. ${ }^{a}$ \\
\hline 4-tOP & 456.0 & 408.0 & 314.3 & 239.5 & 50.3 & 45.3 & 60.4 & 45.5 & 10.1 & 25.4 & 22.0 & 10.4 \\
\hline AO 2246 & 2.1 & 2.0 & 1.5 & 1.2 & 0.9 & 0.4 & 0.6 & 0.8 & n.d. ${ }^{a}$ & n.d. ${ }^{a}$ & n.d. ${ }^{a}$ & n.d. ${ }^{a}$ \\
\hline AO 4426 & n.d. ${ }^{\mathrm{a}}$ & n.d. ${ }^{\mathrm{a}}$ & n.d. ${ }^{a}$ & n.d. ${ }^{\mathrm{a}}$ & n.d. ${ }^{\mathrm{a}}$ & n.d. ${ }^{\mathrm{a}}$ & n.d. ${ }^{\mathrm{a}}$ & n.d. ${ }^{\mathrm{a}}$ & n.d. ${ }^{a}$ & n.d. ${ }^{a}$ & n.d. ${ }^{a}$ & n.d. ${ }^{\mathrm{a}}$ \\
\hline AO 44B25 & 2.4 & 2.1 & 2.0 & 1.1 & n.d. ${ }^{\mathrm{a}}$ & n.d. ${ }^{\mathrm{a}}$ & n.d. ${ }^{\mathrm{a}}$ & n.d. ${ }^{a}$ & n.d. ${ }^{\mathrm{a}}$ & n.d. ${ }^{a}$ & n.d. ${ }^{\mathrm{a}}$ & n.d. ${ }^{\mathrm{a}}$ \\
\hline AO ZKF & n.d. ${ }^{a}$ & n.d. ${ }^{a}$ & n.d. ${ }^{a}$ & n.d. ${ }^{a}$ & n.d. ${ }^{a}$ & n.d. ${ }^{a}$ & n.d. ${ }^{a}$ & n.d. ${ }^{a}$ & n.d. ${ }^{a}$ & n.d. ${ }^{a}$ & n.d. ${ }^{a}$ & n.d. ${ }^{a}$ \\
\hline AO 330 & 14.3 & 14.9 & 13.2 & 13.7 & $-\mathrm{b}$ & $-\mathrm{b}$ & $-\mathrm{b}$ & $-\mathrm{b}$ & $-{ }^{\mathrm{b}}$ & $-\mathrm{b}$ & $-\mathrm{b}$ & $-\mathrm{b}$ \\
\hline
\end{tabular}

a Not detected.

b AO 330 was not included in the analysis of water samples. 


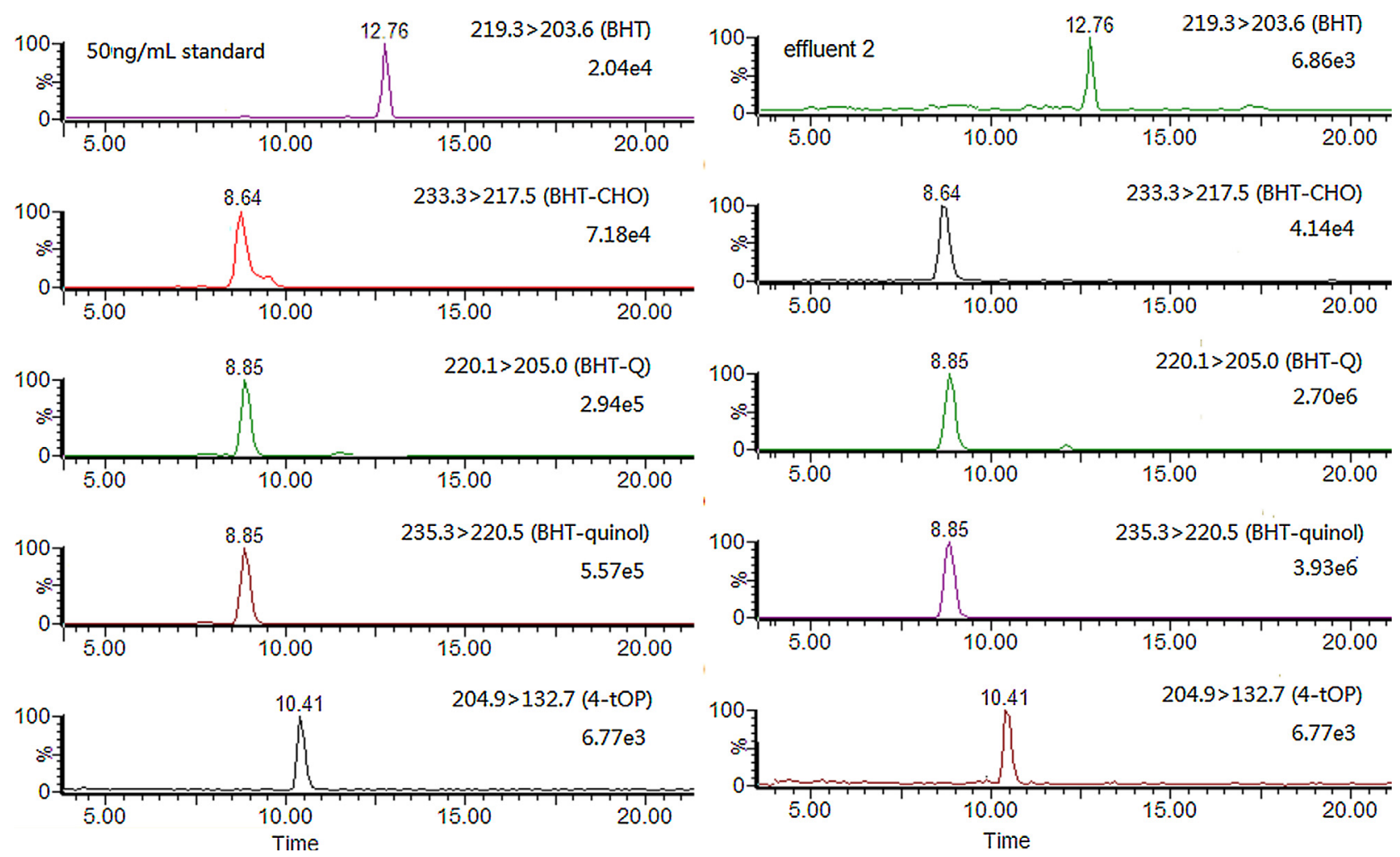

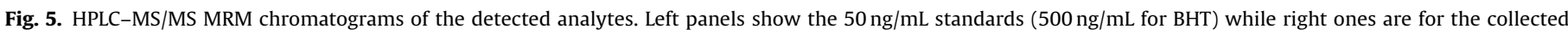
sample of sewage effluent 2 .

result from the cellulose filter ( $30 \mathrm{~mm}$, Dionex) used in the ASE cell after exclusion step by step. The cellulous filters were therefore washed by DCM/Hex $(3: 1, v / v)$ in sonication bath for three times before use, after which no procedural contamination was found during the ASE.

To evaluate the performance of the optimized methods, linearity, sensitivity, recovery and accuracy were taken into account. Results from validation procedures of the analytical methods are shown in Table 2. Least squared regression analysis showed good linearity $\left(R^{2}>0.993\right)$ of the standard calibration curve within the range of $20-2000 \mathrm{ng} / \mathrm{mL}$ for BHT, and $1-1000 \mathrm{ng} / \mathrm{mL}$ for other target analytes in $\mathrm{MeOH}$. High sensitivities were found for all the analytes in this study with MQLs ranged from 0.1 to $23 \mathrm{ng} / \mathrm{L}, 0.1$ to $20 \mathrm{ng} / \mathrm{L}$ and 0.1 to $15 \mathrm{ng} / \mathrm{g}$ for sewage effluent, river water and sludge matrices, respectively.

The recoveries and accuracies of the target analytes were obtained by extracting and analyzing a set of five samples spiked at two different concentrations (40 and $200 \mathrm{ng} / \mathrm{g}$ for sludge samples, 100 and $500 \mathrm{ng} / \mathrm{L}$ for water samples). The spiking levels of BHT were 10 times higher than other analytes. The total recoveries of the target SPAs and BHT metabolites at low spiking level were $63-105 \%, 63-101 \%$ and $70-102 \%$ for sewage effluent, river water and sludge, respectively. Comparable recoveries were found for sewage effluent (65-102\%), river water (63-106\%) and sludge (65-103\%) at high spiking level. The accuracies, expressed as relative standard deviations (RSD, $n=5$ ), were all less than $17 \%$ for the three matrices at both spiking levels. These results indicated that the optimized analytical methods could be applied to the analysis of the target SPAs and BHT metabolites in sewage effluent, river water and sludge samples. To our knowledge, this is the first paper to present a method for analysis of SPAs and BHT metabolites in sludge matrix, and is the first time to determine various emerging
SPAs other than BHT and BHA in sewage effluent and river water matrices.

\subsection{Application in environmental samples}

The optimized methods were applied to the collected sewage sludge, effluent and river water samples. The concentrations of the detected SPAs and BHT metabolites are listed in Table 3. Representative chromatograms of the detected analytes are shown in Fig. 5. Among the 11 target SPAs and BHT metabolites, nine targets including BHT, BHT-CHO, BHT-Q, BHT-quinol, BHA, 4-tOP, AO 2246, AO 44B25 and AO 330 were detected in the sludge samples with concentrations ranging from 1.1 to $2325 \mathrm{ng} / \mathrm{g}$. BHT had the highest concentrations (1400-2325 ng/g) among the detected targets in the sludge samples. Seven targets including BHT, BHT-CHO, BHT-Q BHT-quinol, BHA, 4-tOP and AO 2246 were detected in the sewage effluent samples with concentrations varying from 0.4 to $2510 \mathrm{ng} / \mathrm{L}$. Similar to sludge samples, BHT also dominated the composition profiles of the detected targets in the sewage effluent samples. Five targets (BHT, BHT-CHO, BHT-Q, BHT-quinol and 4-tOP) were found in river water samples with concentration levels between 10.1 and $1621.0 \mathrm{ng} / \mathrm{L}$, which were lower in concentration than the corresponding compounds in sewage effluents $(45.3-2510 \mathrm{ng} / \mathrm{L})$. The concentrations of the five detected targets (BHT, BHT-CHO, BHT-Q, BHT-quinol and 4-tOP) in the upstream river water sample were low (10.1-104 ng/L). After sewage effluent input, the concentrations of the five targets increased to $25.4-1621.0 \mathrm{ng} / \mathrm{L}$ for the river water sample collected at $500 \mathrm{~m}$ downstream site. When the distance from the outlet of WWTP effluent increased to $1000 \mathrm{~m}$ downstream, the concentrations of BHT, BHT-CHO, BHT-Q BHT-quinol and 4-tOP decreased to $22.0-500 \mathrm{ng} / \mathrm{L}$, which further decreased to $10.4-305.0 \mathrm{ng} / \mathrm{L}$ when the distance increased to 
$1500 \mathrm{~m}$. The declining concentration trend in the river water with distance could result from the analyte sorption to suspended matters and sediment.

\section{Conclusions}

In this study, robust analytical methods were developed for the determination of emerging SPAs and metabolites in sewage sludge, effluent and river water samples. ASE was optimized as suitable extraction method for the target analytes in sludge samples. DCM/Hex (3:1, v/v) showed higher extraction efficiency compared with other extraction solvents. Silica gel was chosen for the subsequent clean-up procedure for sludge extract, due to its high target recoveries and high ability in removing interferents compared with other normal phase sorbents. For the water samples, LLE coupled with silica gel clean-up showed higher target recoveries than SPE method. The optimized methods were successfully applied to sewage sludge, effluent and river water samples with nine target analytes identified. The developed methods could be used to evaluate the presence of SPAs and relative metabolites from potential point sources such as WWTPs and their distribution in recipient rivers, which would provide a better understanding of the environmental fates and transport of this kind of emerging pollutants.

\section{Acknowledgments}

We thank the Chinese Academy of Sciences Grants (XDB14010400, YSW2013B01) and National Natural Science Foundation (No. 21207140) for joint financial support.

\section{Appendix A. Supplementary data}

Supplementary data associated with this article can be found, in the online version, at http://dx.doi.org/10.1016/j.chroma.2014. 11.042 .

\section{References}

[1] R. Rodil, J.B. Quintana, G. Basaglia, M.C. Pietrogrande, R. Cela, Determination of synthetic phenolic antioxidants and their metabolites in water samples by downscaled solid-phase extraction, silylation and gas chromatography-mass spectrometry, J. Chromatogr. A 1217 (2010) 6428-6435.

[2] P.G. Demertzis, R. Franz, Development of an HPLC method for measurements of the stability of Irganox-type polymer antioxidants in fatty food stimulants, Z. Lebensm. Unters. Forsch. A 206 (1998) 193-198.

[3] D. Brocca, E. Arvin, H. Mosbæk, Identification of organic compounds migrating from polyethylene pipelines into drinking water, Water Res. 36 (2002) 3675-3680

[4] S. Oikawa, K. Nishino, S. Oikawa, S. Inoue, T. Mizutani, S. Kawanishi, Oxidative DNA damage and apoptosis induced by metabolites of butylated hydroxytoluene, Biochem. Pharmacol. 56 (1998) 361-370.

[5] J. Whysner, G.M. Williams, Butylated hydroxyanisole mechanistic data and risk assessment: conditional species-specific cytotoxicity, enhanced cell proliferation, and tumor promotion, Pharmacol. Ther. 71 (1996) 137-151.

[6] H.G. Kang, S.H. Jeong, J.H. Cho, D.G. Kim, J.M. Park, M.H. Cho, Evaluation of estrogenic and androgenic activity of butylated hydroxyanisole in immature female and castrated rats, Toxicology 213 (2005) 147-156.

[7] K. Satoh, R. Nonaka, D. Nakae, A. Ogata, Increase in in utero exposure to a migrant, 4,4'-butylidenebis(6-t-butyl-m-cresol), from nitrile-butadiene rubber gloves on brain aromatase activity in male rats, Biol. Pharm. Bull. 33 (2010) $6-10$.

[8] O. Takahashi, S. Oishi, Male reproductive toxicity of four bisphenol antioxidants in mice and rats and their estrogenic effect, Arch. Toxicol. 80 (2006) 225-241.

[9] R.S. Lanigan, T.A. Yamarik, Final report on the safety assessment of BHT, Int. J. Toxicol. 21 (2002) 19-94.

[10] F. Hernández, T. Portolés, M. Ibáñez, M.C. Bustos-López, R. Díaz, A.M. BoteroCoy, C.L. Fuentes, G. Peñuela, Use of time-of-flight mass spectrometry for large screening of organic pollutants in surface waters and soils from a rice production area in Colombia, Sci. Total Environ. 439 (2012) 249-259.

[11] E. Fries, W. Püttmann, Monitoring of the antioxidant BHT and its metabolite BHT-CHO in German river water and ground water, Sci. Total Environ. 319 (2004) 269-282.
[12] Y. Gao, Y. Gu, Y. Wei, Determination of polymer additives-antioxidants and ultraviolet (UV) absorbers by high-performance liquid chromatography coupled with UV photodiode array detection in food simulants, J. Agric. Food Chem. 59 (2011) 12982-12989.

[13] G. Alvarez-Rivera, M. Vila, M. Lores, C. Garcia-Jares, M. Llompart, Development of a multi-preservative method based on solid-phase microextraction-gas chromatography-tandem mass spectrometry for cosmetic analysis, J. Chromatogr. A 1339 (2014) 13-25.

[14] US EPA, Estimation Programs Interface Suite ${ }^{\mathrm{TM}}$ V4.10, United States Environmental Protection Agency, DC, USA, 2011

[15] A. González-Antuña, J.C. Domínguez-Romero, J.F. García-Reyes, P. RodríguezGonzález, G. Centineo, J.I.G. Alonso, A. Molina-Díaz, Overcoming matrix effects in electrospray: quantitation of $\beta$-agonists in complex matrices by isotope dilution liquid chromatography-mass spectrometry using singly ${ }^{13} \mathrm{C}$-labeled analogues, J. Chromatogr. A 1288 (2013) 40-47.

[16] V.K.H. Barclay, N.L. Tyrefors, I.M. Johansson, C.E. Pettersson, Trace analysis of fluoxetine and its metabolite norfluoxetine: Part II. Enantioselective quantification and studies of matrix effects in raw and treated wastewater by solid phase extraction and liquid chromatography-tandem mass spectrometry, J. Chromatogr. A 1227 (2012) 105-114.

[17] A. Kruve, A. Künnapas, K. Herodes, I. Leito, Matrix effects in pesticide multiresidue analysis by liquid chromatography-mass spectrometry, J. Chromatogr. A 1187 (2008) 58-66.

[18] J.C. Van De Steene, K.A. Mortier, W.E. Lambert, Tackling matrix effects during development of a liquid chromatographic-electrospray ionisation tandem mass spectrometric analysis of nine basic pharmaceuticals in aqueous environmental samples, J. Chromatogr. A 1123 (2006) 71-81.

[19] J. Wu, X. Qian, Z. Yang, L. Zhang, Study on the matrix effect in the determination of selected pharmaceutical residues in seawater by solid-phase extraction and ultra-high-performance liquid chromatography-electrospray ionization low-energy collision-induced dissociation tandem mass spectrometry, J. Chromatogr. A 1217 (2010) 1471-1475.

[20] R. Liu, T. Ruan, T. Wang, S. Song, M. Yu, Y. Gao, J. Shao, G. Jiang, Trace analysis of mono-, di-, tri-substituted polyfluoroalkyl phosphates and perfluorinated phosphonic acids in sewage sludge by high performance liquid chromatography tandem mass spectrometry, Talanta 111 (2013) 170-177.

[21] O.Zuloaga, P. Navarro, E. Bizkarguenaga, A. Iparraguirre, A. Vallejo, M. Olivares, A. Prieto, Overview of extraction, clean-up and detection techniques for the determination of organic pollutants in sewage sludge: a review, Anal. Chim. Acta 736 (2012) 7-29.

[22] N. Salgueiro-González, I. Turnes-Carou, S. Muniategui-Lorenzoa, P. LópezMahía, D. Prada-Rodríguez, Fast and selective pressurized liquid extraction with simultaneous in cell clean up for the analysis of alkylphenols and bisphenol A in bivalve mollusks, J. Chromatogr. A 1270 (2012) 80-87.

[23] T. Ruan, R. Liu, Q. Fu, T. Wang, Y. Wang, S. Song, P. Wang, M. Teng, G. Jiang, Concentrations and composition profiles of benzotriazole UV stabilizers in municipal sewage sludge in China, Environ. Sci. Technol. 46 (2012) 2071-2079.

[24] M. Klees, E. Hiester, P. Bruckmann, T.C. Schmidt, Determination of polychlorinated biphenyls and polychlorinated dibenzo-p-dioxins and dibenzofurans by pressurized liquid extraction and gas chromatography coupled to mass spectrometry in street dust samples, J. Chromatogr. A 1300 (2013) 17-23.

[25] J. Sun, J. Liu, Q. Liu, G. Qu, T. Ruan, G. Jiang, Sample preparation method for the speciation of polybrominated diphenyl ethers and their methoxylated and hydroxylated analogues in diverse environmental matrices, Talanta 88 (2012) 669-676

[26] H. Zhang, Y. Wang, C. Sun, M. Yu, Y. Gao, T. Wang, J. Liu, G. Jiang, Levels and distributions of hexachlorobutadiene and three chlorobenzenes in biosolids from wastewater treatment plants and in soils within and surrounding a chemical plant in China, Environ. Sci. Technol. 48 (2014) 1525-1531.

[27] M.J. García-Galán, S. Díaz-Cruz, D. Barceló, Multiresidue trace analysis of sulfonamide antibiotics and their metabolites in soils and sewage sludge by pressurized liquid extraction followed by liquid chromatography-electrosprayquadrupole linear ion trap mass spectrometry, J. Chromatogr. A 1275 (2013) $32-40$

[28] P. Herrero, F. Borrull, R.M. Marcé, E. Pocurull, Determination of polyether ionophores in urban sewage sludge by pressurised liquid extraction and liquid chromatography-tandem mass spectrometry: study of different clean-up strategies, J. Chromatogr. A 1285 (2013) 31-39.

[29] C. Ferrer, A. Lozano, A. Agüera, A.J. Girón, A.R. Fernández-Alba, Overcoming matrix effects using the dilution approach in multiresidue methods for fruits and vegetables, J. Chromatogr. A 1218 (2011) 7634-7639.

[30] L. Ramos, Critical overview of selected contemporary sample preparation techniques, J. Chromatogr. A 1221 (2012) 84-98.

[31] R. Liu, T. Ruan, T. Wang, S. Song, F. Guo, G. Jiang, Determination of nine benzotriazole UV stabilizers in environmental water samples by automated on-line solid phase extraction coupled with high-performance liquid chromatography-tandem mass spectrometry, Talanta 120 (2014) $158-166$.

[32] S. Liu, Q. Xie, J. Chen, J. Sun, H. He, X. Zhang, Development and comparison of two dispersive liquid-liquid microextraction techniques coupled to high performance liquid chromatography for the rapid analysis of bisphenol $\mathrm{A}$ in edible oils, J. Chromatogr. A 1295 (2013) 16-23.

[33] L. Zeng, H. Li, T. Wang, Y. Gao, K. Xiao, Y. Du, Y. Wang, G. Jiang, Behavior, fate, and mass loading of short chain chlorinated paraffins in an advanced municipal sewage treatment plant, Environ. Sci. Technol. 47 (2013) 732-740. 